\title{
Research on Laboratory Open Model Against the Background of Innovation and Entrepreneurship Education*
}

\author{
Ye Ye \\ Taizhou University \\ Taizhou, China 225300
}

\begin{abstract}
In recent years, China has begun to implement an innovation-driven development strategy, and the whole society has begun to pay attention to innovation and entrepreneurship. In this context, colleges and universities began to carry out personnel training mode reform, among which experimental teaching reform has become the focus of colleges and universities. In order to strengthen the cultivation of student's innovation ability and practice ability, on the basis of the traditional experimental teaching mode, Taizhou College creates a project oriented practice innovation mode, explores for laboratory open mode, perfects rules and regulations, integrates and shares resources, establishes assessment and incentive mechanism, which has improved students' innovative ability, promoted scientific research and discipline development as well as innovated laboratory systems and mechanisms. It has also promoted innovation through openness, cultivated students' practical innovation ability and achieved certain results in open laboratory teaching reform.
\end{abstract}

Keywords-innovative experimental teaching model; open laboratory

\section{INTRODUCTION}

In the traditional teaching mode of colleges and universities, theoretical teaching and experimental teaching are independent of each other, and teachers and students pay more attention to theoretical teaching, which makes experimental teaching become an auxiliary teaching or a kind of supplement. The general experimental teaching time is very short. The students basically only verify according to the experimental paradigm, and there is no experimental exploration step.

Open laboratory as a new experimental teaching mode against the background of innovation and entrepreneurship education, is different from traditional experimental teaching. Innovative open experiment pays more attention to openness and innovation, and it is open to students in selecting topics, guidance and specific experiments. You can choose the

*Funds: 2018 Industry-University Cooperative Education Project of the Ministry of Education Project number: 201802302016.

Research Fund of Philosophy and Social Science in Universities of Jiangsu Province (Special Subject), Project number: 2018SJA1881.

Taizhou Soft Science Research Project, Project number: RKX201813

Taizhou College 2018 Annual Research Project of Education and Teaching Reform, Project number: 2018JGB16 corresponding experimental platform, experiment time and instructor according to your own interests and needs. In addition, the open experiments are mainly innovative experiments, which can better train students' innovative and thinking ability. This kind of experiment pays more attention to the self-exploration of students, which has certain comprehensiveness and requires students to explore independently. At present, all colleges and universities have begun to carry out innovative open experiments, which is also the future development direction of experimental teaching in colleges and universities.

In the context of innovation and entrepreneurship education, the open laboratory can provide students with sufficient exploration platform, in which students can explore themselves and improve their practical ability in the process of practice. The open laboratory allows more students to understand the current state of science and technology development, improve students' sense of innovation, and allow students to have more choices to carry out various innovative experiments in combination with their own characteristics. In the process of quality education in colleges and universities, open experiment can improve the utilization rate of laboratory and experimental equipment, guide teachers and students to pay more attention to experimental teaching and therefore, lay a foundation for cultivating students with comprehensive ability.

Carrying out innovative experimental teaching is one of the important ways to achieve the purpose of cultivating innovative talents. It is conducive to enhancing students' sense of innovation and allowing students to improve their abilities in the process of practice. This has positive significance for cultivating applied talents as well.

\section{CONSTRUCTION OF INNOVATIVE OPEN EXPERIMENT TEACHING MODE}

At present, in the process of carrying out innovative and open experiments in our school, first of all, the academic affairs office will collect experimental subjects from various teaching units based on the actual situation of our school, and then each teaching unit will apply for corresponding subjects according to its own situation. The academic affairs office will publicize the collected experimental subjects to 
the whole school, and students will choose the corresponding subjects according to their own interests. After completing the selection of the subject, the student will contact the corresponding teacher to agree on the time and place of the experiment. The instructor will introduce the purpose and meaning of the experiment to the students, and then let the students conduct the experiment themselves. Students review the literature, conduct experiments, analyze the results, and ultimately need to submit an experimental report; the teacher will review and guide their reports. Finally, the academic affairs office will check the experimental reports submitted by students and comments submitted by teachers.

The above is the main process of innovative experimental teaching in our school, from which it can be found that the academic affairs office, teachers and students are three core elements, among which the office of academic affairs is mainly responsible for the organization and management of experiments, teachers are mainly responsible for the determination and guidance of experiments, and students explore and discover through experiments. As a teaching management department, the academic affairs office coordinates all teaching units to carry out open experimental teaching through its own organizational ability, and builds a communication and exchange platform for teachers and students, allowing students to choose corresponding open experiments according to their own interests. Teachers are mainly to determine the basic goals and directions of the experiment, to guide students to scientific exploration and to examine and evaluate the students' experimental results. Students conduct experiments in the laboratory through hands-on experiments, and finally submit experimental results to the teaching unit. The combination and collaboration of the above three will enable the ultimate goal of open experimentation and improve students' ability to innovate.

\section{DISCOVERY OF DEFICIENCIES}

At present, our school's innovative open experiment has been carried out within the scope of the whole school, and has achieved certain teaching results in improving students' innovative ability. However, in the actual teaching process, due to various factors, there are still some shortcomings, among which are the following.

\section{A. Propaganda Is Insufficient}

There are major deficiencies in open experimental propaganda. At present, only some students understand that the school is carrying out teaching work in this area while a large number of students don't understand. Students are vague about the specific operational procedures, training objectives, and reporting methods of open experiments.

\section{B. The Formulation of Experimental Topics Needs to Be Improved}

Some teachers have too small a range of topics when formulating experimental topics, which limits students' exploration space. There are also some experimental topics developed by teachers that have too many contents, which may cause students to complete within the specified time frame. There are still some experimental topics that are too difficult and beyond the existing knowledge range and ability level of the students. Therefore, the problems existing in the above aspects need to be further improved.

\section{Students' Enthusiasm and Experimental Initiative Need to Be Improved}

In the process of selecting topics and specific experiments, students are more dependent on teachers. Many students can only complete the experimental tasks prescribed by the teachers and can't explore themselves according to the purpose of the experiment. In the process of experiment, most students still follow the traditional experimental method and carry out experiments according to the experimental process and paradigm. Many students don't explore the relevant issues by themselves, and their operational ability to work is also limited. Although some students have participated in the topic selection, they are not very motivated in the specific experimental process, especially in terms of self-innovation.

In view of the above problems in the open experiment process, it is necessary to conduct an in-depth analysis of the nature and characteristics of the open experiment, and then develop appropriate countermeasures for the cause of the problem, thereby improving the efficiency of the experiment and better cultivating talents with innovative ability.

\section{OPTIMIZATION OF INNOVATIVE OPEN EXPERIMENT TEACHING MODE}

On the basis of the original experimental model, the optimization of the teaching mode is improved on the main problems existing in the teaching, such as teaching organization, experimental topic formulation and experimental guidance and student experiment results evaluation as well.

\section{INNOVATIVE LABORATORY OPEN MANAGEMENT MODE IMPROVEMENT EXPLORATION}

\section{A. Establishing an Open Sharing System and Management System}

In order to more normatively manage open experiment selection and guidance, and facilitate student selection and teacher review, the innovative laboratory has specially developed an experimental management platform, which allows students to conduct course selection and appointment experiments, and can automatically complete registration management operations according to student selection information, so that the student selection information and experimental teaching information can be managed through this unified platform.

In order to facilitate the management of system and laboratory resources, the laboratory has set up a laboratory assistant, which will manage the student's experimental appointments, equipment and other resources to regulate the management of the laboratory. In order to better standardize 
students' experiments, our school has also specially formulated open laboratory and innovative laboratory-related management regulations to ensure the safe and orderly conduct of experimental teaching.

In order to ensure the safety of students and laboratories, as well as to protect laboratory equipment and various resources, the laboratory has made clear regulations on equipment use, laboratory appointment and management, laboratory waste treatment, laboratory registration management, etc., and also has detailed equipment use method. In the teaching process, students and teachers need to conduct experiments in strict accordance with the norms and requirements, so as to ensure the safe and orderly conduct of experiments.

\section{B. Opening of the Teaching Experiment Project}

The experimental experiment plan for the semester of the laboratory is formulated according to the laboratory arrangement. The laboratory management plan is clearly defined and publicized to the whole school. Specific teaching plans and experimental topics are also announced to students. This includes information on the specific experimental topics, content, and time and location of the experiment. Most of the experiments in the teaching plan are easy to implement, and at the same time have certain innovative practical values. Students are easy to carry out relevant experiments.

\section{Opening of Innovative and Scientific Research Project}

Innovative scientific research experiments have high requirements on students' knowledge scope and practical ability. Therefore, they are mainly aimed at senior undergraduates. Through open experiments, these students are guided to carry out scientific research and exploration, and participate in scientific research activities to cultivate their innovative consciousness and improve their practical ability. This type of experiment is mainly based on the teacher's own research work and plans. Students conduct relevant experiments through self-learning and exploration and then analyze the results.

\section{Competition and Open Extracurricular Activities}

In order to facilitate the development of innovative experiments, the teaching center has set up an innovative work laboratory according to actual needs, which provides the necessary tools, equipment and laboratory materials for students to carry out experiments. The experimental platform is open to all students and focuses on supporting the student team participating in the competition. In order to better serve the student competition team, the laboratory also hires an instructor to guide them. Excellent teams will be recommended to national or international competitions to stimulate students' interest in participation and enhance their ability to innovate and practice. By gathering excellent teaching resources, hiring high-level teachers, providing advanced experimental equipment and other experimental conditions, the laboratory enables students to train themselves so as to improve their comprehensive quality. In the process of counseling, teachers should guide students to conduct cutting-edge scientific inquiry from the perspective of innovation, and improve students' practical ability and scientific research ability by leading them to participate in actual scientific research training. The student team participating in the science and technology competition, with the guidance of the instructor and the full support of the laboratory, will have the opportunity to compete with the top domestic college students in the same stage, so that they can accumulate experience in the competition and improve their practical and innovative ability.

\section{E. Exploring School-enterprise Collaborative Innovation}

In order to make full use of the resources inside and outside the school, to provide students with better experimental conditions, the school should strengthen communication and cooperation with enterprises and laboratories inside and outside the school, and through the in-depth cooperation with well-known enterprises to jointly build a joint laboratory. In this way, students can be trained with the help of corporate funds and technologies and they can also be provided with a platform for practice. The joint laboratory will introduce advanced technology from enterprises, and be equipped with perfect experimental hardware, so that students can improve their ability and quality in practice, which can also cultivate excellent talents for enterprises. School-enterprise collaborative innovation will give full play to the advantages of the school and the enterprise, allowing students to access to cutting-edge technologies and production practices. It will provide a lot of resources for the development of school experimental bases and student development by inviting companies to participate in the creation of joint experiments. Under the mode of school-enterprise collaborative innovation, it is necessary to strengthen the management of students' experimental teaching and actively communicate and cooperate with enterprises, so as to provide excellent talents for enterprises and achieve the goal of win-win situation between the university and enterprises.

\section{F. Establishing Assessment and Incentive Mechanism}

In order to improve the level of experimental teaching, it is necessary to develop a scientific and reasonable incentive system, which can improve the enthusiasm of teachers and students and allow more students to participate in open experiments. The incentive system is mainly divided into assessment and reward and punishment systems, in which student assessment is mainly the assessment of the performance of its experimental courses. Comprehensive investigations are needed from the aspects of student experimental design, experimental operation and analysis of experimental results. Rewards can be given to outstanding students for course grades, credits, and scholarships.

\section{CONCLUSION}

In response to the call of the state and the Ministry of Education to enhance students' ability to innovate and practice, Taizhou College begins innovative experiments to provide a platform for self-exploration and practice for all students. This paper studies and analyzes the main problems existing in the current experimental innovation teaching in 
schools. Firstly, it introduces the relevant situation of open experimental teaching and summarizes the background and current situation of open experimental teaching in schools. The main reasons for the problems in the current open experiment are analyzed. The study finds that the current school still has shortcomings in terms of propaganda and experimental guidance. In view of these problems, this paper suggests that schools should provide better experimental teaching environment for students by standardizing experimental management and strengthening schoolenterprise cooperation, so as to improve students' innovation and practical ability.

\section{REFERENCES}

[1] Yang Xianmin, Luo Jiaojiao, Liu Yaxin, et al. Data-Driven Teaching: A New Trend of Teaching Paradigm in the Age of Big Data[J]. Research in Audio-Visual Education, 2017, 38(12):13-20, 26. (in Chinese)

[2] Jia Shuanglin, Chu Yaxu, Chen Xue. Implementation and Management of Local College Students' Innovation and Entrepreneurship Training Program [J]. Laboratory Research and Exploration, 2017, 36 (7): 242-245, 256. (in Chinese)

[3] Li Shuangshou, Li Lefei, Sun Hongbin, et al. The Construction of the Innovation and Entrepreneurship Training System of "Trinity, ThreeCreation Integration" [J]. Tsinghua University Education Research, 2017, 38 (2) : 111-116. (in Chinese)

[4] Qian Xiaoming. Exploration and Practice of the Open Management Mechanism of University Laboratories [J]. Experimental Technology and Management, 2013, 30(11): 40-49. (in Chinese)

[5] Hu Haishan, Du Wenbo, Chen Ping. Analysis on the Path of Integrating Innovation and Entrepreneurship Education into the Whole Process of Talent Cultivation in Colleges and Universities [J]. Experimental Technology and Management, 2017, 34(9): 27-29. (in Chinese)

[6] Di Kui, Zhang Xiao, Chen Chen. Exploration and Practice of the Construction of Experimental Teaching Demonstration Center in Colleges [J]. Experimental Technology and Management, 2018, 35(6): 226-230. (in Chinese)

[7] Chen Linjiao, Shi Yan, Li Qinxi, et al. Comprehensive Education Function of National-level Experimental Teaching Demonstration Center [J]. Experimental Technology and Management, 2018, 35(6): 222-225. (in Chinese) 